\title{
Study of Prevalence of Nonalcoholic Fatty Liver Disease in Type II Diabetes Mellitus Patients and Variations in Liver Enzymes and Lipid Profile in Diabetic Patients with Fatty Liver in Comparison With Patients Without Fatty Liver
}

\author{
OSAM SAEED ABDO GABALI, M.D. \\ The Department of Internal Medicine, Faculty of Medicine and Health Sciences, Aden University
}

\begin{abstract}
Background: Type 2 diabetes mellitus (T2DM) patients potentially are at risk of developing non-alcoholic fatty liver disease (NAFLD), Non-alcoholic fatty liver disease (NAFLD) is the most prevalent chronic liver disease in developing and developed countries, Global prevalence of NAFLD is $25.24 \%$ with highest prevalence in the Middle East and South America and lowest in Africa.
\end{abstract}

Aim of Study: This study aimed to determine the prevalence of NAFLD among T2DM patients, diagnosed by ultrasonography of liver, to study the age, sex in NAFLD and to compare liver enzymes and lipid profile between individuals with NAFLD and without NAFLD.

Patients and Methods: A prospective study was conducted of 100 type 2 diabetic Patients visited a private clinic in Aden republic of Yemen, in the period from October 2017 to June 2018.

Results: Total of (100 patients) type 2 diabetes mellitus ambulatory patients were selected for the study. 62 patients $(62 \%)$ had NAFLD and 38 patients $(38 \%)$ had normal liver on ultrasonography, the prevalence of NAFLD in the present study was $62 \%$, Majority of the study population observed with type 2 diabetes mellitus and NAFLD were females $(n=40$, $65 \%$ ), and 22 were males (35\%), the age range of diabetic patients with NAFLD was 40-65 years, mean age 53.16 SD \pm 7.64 , Subjects with diabetes mellitus and NAFLD had significant elevation in Alanine transaminase (ALT), cholesterol, LDL, and triglyceride than diabetic subjects without NAFLD.

Conclusions: Early detection and optimum control of diabetes mellitus is important to minimize the effect of diabetes on liver. Hence, assay of serum levels of hepatic enzymes, and abdominal ultrasound to detect NAFLD should be done in all patients with T2DM as preliminary diagnostic tests.

Key Words: Nonalcoholic fatty liver disease-Liver enzymesLiver function - Type 2 diabetes mellitus.

Correspondence to: Dr. Osam Saeed Abdo Gabali, The Department of Internal Medicine, Faculty of Medicine and Health Sciences, Aden University

\section{Introduction}

NAFLD is a type of chronic liver disorder, which is gaining significance worldwide. Most of the patients with NAFLD are asymptomatic, although some may experience fatigue, malaise or pain in the right hypochondriac region of abdomen. Hepatomegaly is the common finding in majority of patients. The definitive diagnosis of NAFLD is based on the histological examination of liver biopsy, but it is an invasive and costly procedure and is associated with many complications. Hence, NAFLD is generally diagnosed by most widely available ultrasonography examination that has a sensitivity of $90 \%$ and specificity of $95 \%$ in detection of moderate and severe cases [1]

Nonalcoholic fatty liver disease (NAFLD) is the most common cause of liver disease worldwide with prevalence estimates ranging from $25 \%$ to $45 \%$ in most studies, increasing in parallel with that of obesity and diabetes, Nonalcoholic fatty liver disease was first described in 1980 and is divided into the histological categories of:

Nonalcoholic fatty liver, which includes patients with isolated hepatic steatosis and patients with steatosis and mild nonspecific inflammation, and nonalcoholic steatohepatitis, which is distinguished from the former by the additional presence of features of hepatocellular injury with or without fibrosis, the presence of hepatic fibrosis is the most important determinant of outcome [2]

Non-alcoholic fatty liver disease (NAFLD) and type 2 diabetes (T2DM) are common conditions that regularly co-exist and can act synergistically to drive adverse outcomes. The presence of both NAFLD and T2DM increases the likelihood of the 
development of complications of diabetes (including both macro- and micro-vascular complications) as well as augmenting the risk of more severe NAFLD, including cirrhosis, hepatocellular carcinoma and death [3]

NAFLD occurs in up to $20 \%$ of the general population and possibly up to $90 \%$ in obese patients 5. NAFLD presents a wide spectrum of lesions that include steatosis, hepatitis and fibrosis. These three types of lesions can occur in different grades in the same patient. In the presence of fibrosis, progression to cirrhosis and hepatocellular carcinoma may occur in $20 \%$ and $10 \%$ of cases, respectively 1 [4].

The highest prevalence of NAFL is in the Middle East and South America and lowest in Africa. Metabolic comorbidities associated with NAFLD included obesity (51.34\%; 95\% CI: 41.38-61.20), type 2 diabetes ( $22.51 \%$; 95\% CI: 17.92-27.89), hyperlipidemia (69.16\%; 95\% CI: 49.91-83.46\%), hypertension $(39.34 \%$; $95 \%$ CI: $33.15-45.88)$ and metabolic syndrome $(42.54 \%$; $95 \%$ CI: $30.06-$ 56.05) [5].

The criteria for definition of NAFLD requires that (a) there is evidence of hepatic steatosis, either by imaging or by histology and (b) there are no causes for secondary hepatic fat accumulation such as significant alcohol consumption, use of steatogenic medication or hereditary disorders [6]

Abdominal ultrasound scans are the most frequently used imaging tool for diagnosing NAFLD. Five point ultrasonography criteria of diagnosis of fatty liver disease recommended by Dasharty's was used to diagnose NAFLD: (1) Increased hepatic brightness" or hyper echogenicity (He), (2) Posterior attenuation of the right lobe (RLpA), (3) Increased contrast between the right kidney and liver (HRC), (4) Loss of visualization of right diaphragm and (5) Diminished visibility of the intrahepatic vessels [7].

\section{Patients and Methods}

This was a prospective study carried out in a private clinic in Aden-Yemen, over a period of nine months, from October 2017 to June 2018.

100 subjects of type $2 \mathrm{DM}$ were recruited into study, Descriptive data like name, age, sex, were obtained by interviewing the patients. All patients were subjected for the estimation of liver enzymes as aspartate transaminase (AST), alanine aminotransferase (ALT), fasting lipid profile, which includes total cholesterol, triglycerides, highdensity lipoprotein cholesterol (HDL-C), and lowdensity lipoprotein cholesterol (LDL-C), at the time of inclusion into the study. NAFLD was diagnosed on ultrasonography.

Inclusion criteria which were opted for this study: (1) Type 2 diabetics mellitus, (2) Age $\geq 40$ years, (3) Bright liver on ultrasound imaging.

Subjects with history of qat chewing, alcohol intake, history of systemic illnesses known to cause fatty liver disease, and those who were receiving or had recently received drugs (including herbal medicines) known to raise liver enzymes or cause fatty liver disease were excluded from this study.

After diagnosing Non-Alcoholic Fatty Liver Disease (NAFLD) by ultrasound, patients were grouped into two groups, Group I with DM type 2 with NAFLD and Group II with DM type 2 without NAFLD.

Subjects did not have a liver biopsy and histological examination. Performance of this invasive procedure was not feasible; we used ultrasound to detect fatty liver in our study.

The parameters adopted for abnormal values were, cholesterol $\geq 200 \mathrm{mg} / \mathrm{dl}$, triglycerides $\geq 150 \mathrm{mg}$ $/ \mathrm{dl}, \mathrm{LDL} \geq 150 \mathrm{mg} / \mathrm{dl}$, HDL $<40 \mathrm{mg} / \mathrm{dl}$ for men and $<50 \mathrm{mg} / \mathrm{dl}$ for women [4]. Serum liver enzymes ALT, AST, were estimated by modified IFCC method, and normal kit ranges were ALT: 10-40 international units per liter (IU/L), AST: 10-35 IU/L, [8].

The size of the liver was measured in midclaviclar line longitudinally and $<14 \mathrm{~cm}$ was taken as controls and $>14$ was considered as hepatomegaly [1].

All the subjects underwent abdominal ultrasonography by the radiologist for evidence of fatty liver through the standard criteria. The standard criteria accepted by the American gastroenterology association is an increase in hepatic echogenicity as a reference, the presence of enhancement and lack of differentiation in the periportal intensity and the vascular wall due to great hyper echogenicity in the parenchyma [9].

Data were expressed as mean $\pm \mathrm{SD}$. $p$-value $<0.05$ is considered as statistically significant. Statistical analysis was performed using SPSS 21.0s.

Ethical consideration: Verbal informed consent was obtained from all participating subjects. The 
research and ethics committee in the faculty of medicine university of Aden approved the study design.

\section{Results}

The present study was conducted in a private clinic, from October 2017 to June 2018, 100 subjects of type $2 \mathrm{DM}$ were recruited into study.

Table (1) showed 62 patients (62\%) had NAFLD and 38 patients $(38 \%)$ had normal liver on ultrasonography, the prevalence of NAFLD in the present study was $62 \%$.

Table (2) showed a prominence of female gen$\operatorname{der}(n=40,65 \%)$ versus $(n=22,35 \%)$ being male.

Table (3) showed the age range of diabetic patients with NAFLD, Their age ranged from 4065 years, mean age $53.16 \mathrm{SD} \pm 7.64$.

Age group (50-59) constitute ( $\mathrm{n}=26,41.93 \%)$.

Table (4) revealed Subjects with NAFLD had higher ALT, AST, than subjects without NAFLD.

In group 1 patients with DM type 2 and NAFL, ALT was significantly increased when compared to group 2 patients, while AST was also increased but not significant.

Table (5) revealed group 1 patients with type $2 \mathrm{DM}$ and NAFL, Cholesterol, Triglycerides, LDL cholesterol were significantly increased when compared to group 2 patients.

Table (1): Prevalence of NAFL among Type 2 DM.

\begin{tabular}{lcc}
\hline & No. of patients & $\%$ \\
\hline Type 2 DM with NAFL & 62 & 62 \\
Type 2 DM without NAFL & 38 & 38 \\
\hline Total & 100 & 100 \\
\hline
\end{tabular}

Table (2): The sex distribution among Type 2 DM with NAFL.

\begin{tabular}{lcl}
\hline Sex & No. of patients & $\%$ \\
\hline Female & 40 & 65 \\
Male & 22 & 35 \\
\hline Total & 62 & 100 \\
\hline
\end{tabular}

Table (3): Age distribution among diabetic patients with NAFL.

\begin{tabular}{ccl}
\hline Age group & No. & $\%$ \\
\hline $40-49$ & 19 & 30 \\
$50-59$ & 26 & 41.9 \\
$>60$ & 17 & 27 \\
\hline
\end{tabular}

Table (4): Liver enzymes variants among diabetic patients with NAFL and without NAFL.

\begin{tabular}{|c|c|c|c|c|c|}
\hline & \multicolumn{4}{|c|}{ DM with NAFL DM without NAFL } & \multirow{2}{*}{$\begin{array}{c}p- \\
\text { value }\end{array}$} \\
\hline & Mean & $\pm \mathrm{SD}$ & Mean & $\pm \mathrm{SD}$ & \\
\hline ALT & 35.0 & 14.5 & 27.2 & 11 & 0.03 \\
\hline AST & 70.0 & 22.0 & 32.3 & 17.4 & 0.06 \\
\hline
\end{tabular}

Table (5): Lipid profile variants among diabetic patients with NAFL and without NAFL.

\begin{tabular}{lllllll}
\hline & \multicolumn{2}{c}{ DM with NAFL } & \multicolumn{2}{c}{ DM without NAFL } & $p$ - \\
\cline { 2 - 5 } & Mean & \pm SD & Mean & \pm SD & \\
\hline Cholesterol & 223.6 & 44.1 & 182.9 & 17.1 & 0.0001 \\
LDL & 148 & 39.8 & 107 & 25.7 & 0.03 \\
Triglyceride & 197 & 38.8 & 162.9 & 13.8 & 0.0001 \\
HDL & 35.3 & 6.7 & 37.9 & 6.8 & 0.06 \\
\hline
\end{tabular}

\section{Discussion}

The prevalence of Nonalcoholic fatty liver disease in type 2 Diabetes Mellitus was found to be $62 \%$ in our study. Close to the result of Raminderpal Singh Sibia and his colleges in a study published in the National Journal of Laboratory Medicine demonstrated that, NAFLD was prevailed in $(61 \%)$ among 100 patients of type 2 diabetes mellitus [10].

Targher et al., [11] and Agarwal et al., [12] also found high prevalence of NAFLD among diabetics as $69.5 \%, 87 \%$ respectively.

In our present study, prevalence of NAFLD was higher than the result mentioned in Nagaraj et al., 2016 [1] and Prashanth $\mathrm{M}$ et al., [13]. Where prevalence of nonalcoholic fatty liver was $52 \%$ and $57.2 \%$ respectively.

It was observed, out of 62 cases of NAFLD, $40(65 \%)$ were females, and $22(35 \%)$ were males, Thus the prevalence was higher in females. With $p$-value was 0.5 , which was not significant similar to the result conducted in western India by Shailaja v Rao and Kusum K Sikariya in among 77 patients with type 2 diabetes mellitus and NAFLD, The prevalence of NAFLD was more in females $64.9 \%$ (50/77) which was statistically not significant Shailaja v Rao and Kusum K Sikariya 2016 [14] Similar study conducted by merat et al showed the prevalence of NAFLD was higher among women $(60.1 \%)$ than men $(44.8 \%)$ which was also not statistically significant $p=0.069$ [15]

The range of age among diabetic patients with NAFLD was 40-65 years, mean age 53. $16 \mathrm{SD} \pm$ 
7.64, $p$-value significant (0.0001), similar result was found in the study made by Raminderpal Singh Sibia et al., Mean age of type 2 diabetes mellitus and NAFLD was 55.64 \pm 11.653 and $p$-value was also statistically significant (0.002) [10].

In our present study, ALT was significantly increased ( $p$-value .003) in type 2 diabetes mellitus patients with NAFLD When compared to type 2 diabetes mellitus patients without NAFL. While AST was not significantly increased ( $p$-value 0.06 )

Elmahi and Abdrabo reported in their study that, raised ALT levels are the most common abnormality Email HM and Abdrabo AA [16] while in Nagaraj S et al., [1] and Prabhudeva $\mathrm{N}$ et al., [17].

AST, ALT, were both significantly increased in type 2 diabetes mellitus patients with NAFLD.

In the study reported from western India by Shailaja v Rao and Kusum K Sikariya, patients had liver enzymes almost within normal range but the mean values were higher making it statistically significant [14].

Cholesterol, Triglycerides and LDL cholesterol were statistically significantly increased in group 1 patients when compared to group 2 patients $(p-$ value $<0.0001)$, $(p$-value $<0.0001),(p$-value $<0.03)$ respectively, while HDL $p$-value was not significant (0.06).

In the study made by Shailaja and Kusum in a Tertiary Care Centre In Western India, the difference in triglyceride in NAFLD and in non-NAFLD diabetic patients was found statistically significant ( $p$-value 0.011) like our present study, while cholesterol in NAFLD was statistically not significant ( $p$-value 0.162 ). The difference was very highly significant between Mean HDL in NAFLD group and in non-NAFLD group $p$-value 0.000 [14], while in the present study, HDL $p$-value was not significant 0.06 .

Nagaraj et al., study revealed that Cholesterol and Triglycerides In group 1 patients were significantly increased when compared to group 2 patients [1]

\section{References}

1- NAGARAJ S., SUNITHA S. KIRAN, RAJEEV GANDHAM, WILMA DELPHINE SILVIA C.R., NAGARAJA M.R., ABDUL NASAR S. and BISWAJIT DAS.: Study of prevalence of nonalcoholic fatty liver disease in type 2 diabetes mellitus patients and variations in liver function tests, lipid profile and mean platelet volume in patients with fatty liver in comparison with patients without fatty liver, Int. J. Res. Med. Sci. Mar., 4 (3): 871-876, 2016.

2- MARY E. RINELLA: Nonalcoholic Fatty Liver Disease A Systematic Review, JAMA. Volume 313, Number (22): 2263-2273. doi:10.1001/jama.2015.5370, June 9, 2015.

3- JONATHAN M. HAZLEHURST A. CONOR WOODS A. THOMAS MARJOT B. JEREMY F., COBBOLD B and JEREMY W. TOMLINSONA: Non-alcoholic fatty liver disease and diabetes. Aug., 65 (8): 1096-1108, 2016.

4- FERNANDO DE BARROS, SERGIO SETUBAL, JOSÉ MANOEL MARTINHO, LORAINE FERRAZ and ANDRESSA GAUDENCIO: Correlation of non-alcoholic fatty liver disease and features of metabolic syndrome in morbidly obese patients in the preoperative assessment of bariatric surgery, 29 (4): 260-263, 2016.

5- YOUNOSSI Z.M., KOENIG AB, ABDELATIF D., FAZEL Y., HENRY L. and WYMER M.: Global epidemiology of nonalcoholic fatty liver disease-Meta-analytic assessment of prevalence, incidence, and outcomes Jul., 64 (1): 73-84. doi: 10.1002/hep.28431. Epub., 2016.

6- CHALASANI N., YOUNOSSI Z., LAVINE J.E., DIEHL A.M., BRUNT E.M. and CUSI K.: The diagnosis and management of non-alcoholic fatty liver disease: Practice guideline by the American Gastroenterological Association, American Association for the Study of Liver Diseases, and American College of Gastroenterology. Gastroenterology, 142: 1592-609, 2012.

7- DASARATHY S., DASARATHY J., KHIYAMI A., JOSEPH R., LOPEZ R. and MCCULLOUGH A.J.: Validity of real time ultrasound in the diagnosis of hepatic steatosis: A prospective study. J. Hepatol., 51: 1061-7. 2009.

8- DEBMALYA SANYAL, PRADIP MUKHERJEE, MOU TUSI RAYCHAUDHURI, SUJOY GHOSH, SATINATH MUKHERJEE and SUBHANKAR CHOWDHURY: Profile of liver enzymes in non-alcoholic fatty liver disease in patients with impaired glucose tolerance and newly detected untreated type 2 diabetes, 19 (5): 597-601, 2015.

9- GAHARWAR R., TRIKHA S., MARGEKAR S.L., JATAV O.P. and GANGA P.D.: Study of Clinical Profile of Patients of Nonalcoholic Fatty Liver Disease and its Association with Metabolic Syndrome, Journal of the Association of Physicians of India. Jan., 63: 13, 2015.

10- RAMINDERPAL SINGH SIBIA, SANDEEP DHOOT, PREETKANWAL SIBIA, SOURABH MURARKA, HARNOOR BHARDWAJ and AKASH DEEP AGGARWAL: Non-Alcoholic Fatty Liver Disease in T2DM, National Journal of Laboratory Medicine, 5 (4): IO11IO13, 2016.

11-TARGHER G., BERTOLINI L., PADOVANI R., RODELLA S., TESSARI R. and ZENARI: Prevalence of nonalcoholic fatty liver disease and its association with cardiovascular disease among type 2 diabetic patients. Diabetes Care., 30 (5): 1212-18, 2007.

12- AGARWAL A.K., JAIN V., SINGLA S., BARUAH B.P., ARYA V. and YADAV R.: Prevalence of non-alcoholic fatty liver disease and its correlation with coronary risk factors in patients with type 2 diabetes. J. Assoc. Physicians India, 59: 351-54, 2011. 
13- PRASHANTH M., GANESH H.K., VIMA M.V., JOHN M. and BANDGAR T.: Prevalence of nonalcoholic fatty liver disease in patients with type 2 diabetes mellitus. J. Assoc. Physicians India, 57: 205-10, 2009.

14- SHAILAJA V RAO* and KUSUM K SIKARIYA: Prevalence and Risk Factors of Nonalcoholic Fatty Liver Disease in Type 2 Diabetes Mellitus in a Tertiary Care Centre In Western India, IOSR Journal of Dental and Medical Sciences, 15 (2): 1-7, 2016.

15- MERAT S., YARAHMADI S., TAHAGHOGHI S., ALIZADEH Z., SEDIGHI N., MANSOURNIA N., GHOR-
BANI A. and MALEKZADEH R.: Prevalence of fatty liver disease among type 2 diabetes mellitus patients and its relation to insulin resistance. Middle East Journal of Digestive Diseases MEJDD, 1 (2): 74-9, 2009.

16- ELMAHI H.M. and ABDRABO A.A.: Determinants of abnormal liver function tests in Diabetes Type 2 patients in Sudan. Journal of Science, 4 (1): 459, 2014.

17- PRABHUDEVA N. and GHOUSE P. MOUNIKA K.: Hepatic Dysfunction in Diabetes Mellitus: Biochemical and Ultrasonological Study. Journal of Academia and Industrial Research, 3 (4): 164-7, 2014.

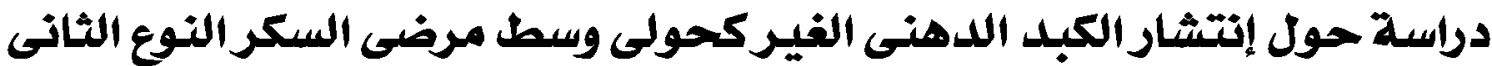

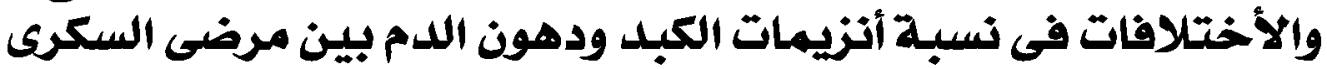

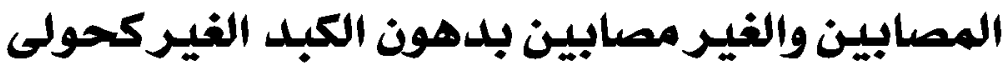

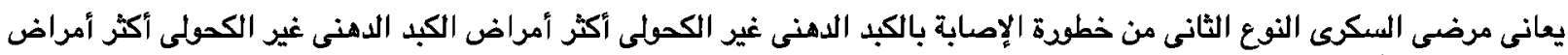

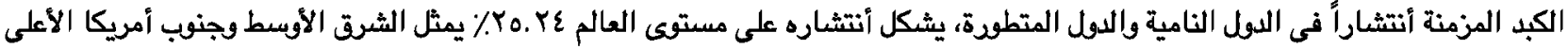
أنثاراً وتمثل أفريقيا الأقل أنتشاراً.

الأهداف: هدفت الدراسة لتحديد مدى أنتشار دهون الكبد غير الكحولى وسط مرضى السكرى النهي النوع الثانى مستخدماً جهاز الموجات

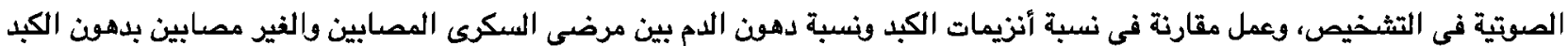
غير الكحولى.

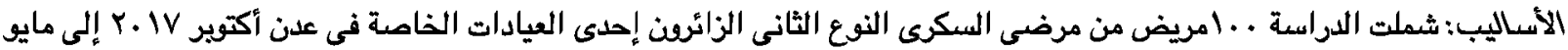

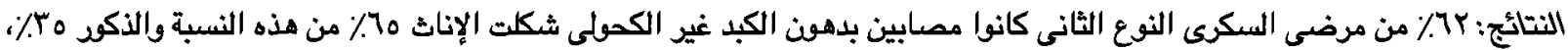

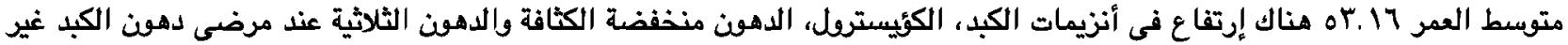
الكحولى.

الأستتاج: يعتبر التشخيص البكر وتنظيم السكر من أهم العوامل لتخفيف أثر السكر على الكبد، لهذا كل مرضى السكرى النوع الثانى

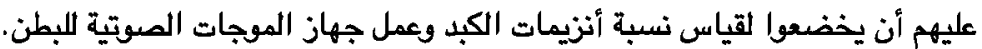

